\title{
Resistência de cultivares de trigo à giberela mediante inoculação artificial em espiguetas
}

\author{
Carolina Cardoso Deuner ${ }^{1}$, Eduardo Viana ${ }^{2,4}$, Juliane Nicolodi Camera ${ }^{2}$, Erlei Melo Reis ${ }^{3}$
}

${ }^{1}$ Eng $^{\mathrm{a}}$ Agr ${ }^{\mathrm{a}}$ Doutora Professora do Curso de Agronomia e Pós-graduação em Agronomia - Faculdade de Agronomia e Medicina Veterinária Universidade de Passo Fundo, Campus I, Bairro São José - BR 285 - KM 171, Caixa Postal 611, Passo Fundo, RS, Brasil. CEP $99052-900$. (autor para correspondência). ${ }^{2}$ Estudante do PPGAgro - Laboratório de Fitopatologia - Faculdade de Agronomia e Medicina Veterinária - Universidade de Passo Fundo. ${ }^{3} \mathrm{Eng}^{\mathrm{o}}$. Agr ${ }^{\circ}$. Doutor. Pesquisador da OR Melhoramento de Sementes Ltda, Avenida Rui Barbosa, 1300, 99050-120, Passo Fundo, RS, Brasil; erleireis@upf.br. ${ }^{4}$ Este trabalho é parte da dissertação de mestrado do segundo autor.

Autor para correspondência: Carolina Cardoso Deuner (carolinadeuner@upf.br)

Data de chegada: 10/04/2014. Aceito para publicação em: 04/05/2015.

$10.1590 / 0100-5405 / 1994$

\section{RESUMO}

Deuner, C.C.; Viana, E.; Camera, J.N.; Reis, E.M. Resistência de cultivares de trigo à giberela mediante inoculação artificial em espiguetas. Summa Phytopathologica, v.41, n.3, p.202-206, 2015.

Este trabalho teve como objetivo determinar a concentração ótima de conídios de F. graminearum para inoculação artificial em espiguetas de trigo e verificar o tipo de resistência à giberela (Tipo I e/ou II) dos cultivares de trigo. $\mathrm{O}$ trabalho foi composto por dois experimentos, sendo que no primeiro determinou-se a concentração ótima de conídios $\mathrm{mL}^{-1}$ para inoculação artificial em quatro cultivares. Para isso, testou-se as concentrações de $5 \times 10^{3}, 15 \times 10^{3}$, $25 \times 10^{3}, 35 \times 10^{3}$ e $40 \times 10^{3}$ conídios $\mathrm{mL}^{-1}$. Vinte e um dias após a inoculação quantificou-se a incidência de $F$. graminearum em espiguetas, sendo que através de análise de regressão, determinou-se a concentração ótima de conídios $\mathrm{mL}^{-1}$ para cada cultivar. No segundo experimento, avaliou-se a resistência à giberela dos cultivares de trigo mediante inoculação artificial, utilizou-se a mesma metodologia do experimento anterior e a concentração de $31 \times 10^{3}$ conídios $\mathrm{mL}^{-}$

${ }^{1}$. As variáveis avaliadas foram severidade, grão giberelados e incidência em espiguetas gibereladas. A melhor concentração para inoculação artificial de giberela em espiguetas de trigo é de $31 \times 10^{3}$ conídios $\mathrm{mL}^{-1}$. A maior severidade da doença foi verificada para os cultivares de trigo BRS 208 e Pampeano e a maior percentagem de grão giberelado foi para o cultivar BRS 208. Os cultivares Pampeano e BRS 177 não apresentaram resistência do Tipo I à giberela, porém apresentam do Tipo II, enquanto que os cultivares Mirante e BRS 208 não apresentam nenhum dos dois tipos de resistência.

Palavras-chave: Gibberella zeae, concentração de inóculo, resistência Tipo II.

\section{ABSTRACT}

Deuner, C.C.; Viana, E.; Camera, J.N.; Reis, E.M. Resistance of wheat cultivars to head blight by means of artificial inoculation in spikelets.. Summa Phytopathologica, v.41, n.3, p.202-206, 2015.

This study aimed to determine the optimal concentration of $F$. graminearum conidia for artificial inoculation in wheat spikelets and to verify the type of head blight resistance (Type I and / or II) in wheat cultivars. The study consisted of two experiments, and in the first one, the optimal concentration of conidia $\mathrm{mL}^{-1}$ was determined for artificial inoculation in four cultivars. Thus, the tested concentrations were $5 \times 10^{3}, 15 \times 10^{3}, 25 \times 10^{3}, 35 \times 10^{3}$ and $40 \times 10^{3}$ conidia $\mathrm{mL}^{-1}$. Twenty-one days after inoculation, the incidence of $F$. graminearum in spikelets was quantified, and regression analysis was used to determine the optimal concentration of conidia $\mathrm{ml}^{-1}$ for each cultivar. In the second experiment, the resistance of wheat cultivars to artificially inoculated head blight was evaluated, using the same methodology adopted in the previous experiment and the concentration of $31 \times 10^{3}$ conidia $\mathrm{mL}^{-1}$. The evaluated variables were severity, affected grains and incidence in affected spikelets. The best concentration for artificial inoculation of head blight in wheat spikelets is $31 \times 10^{3}$ conidia $\mathrm{mL}^{-1}$. The greatest severity of the disease was observed for wheat cultivars BRS 208 and Pampeano, and the highest percentage of affected grains was noted for BRS 208. The cultivars Pampeano and BRS 177 did not show Type I resistance to head blight but had Type II resistance, while the cultivars Mirante and BRS 208 had neither of the resistance types.

Additional keywords: Gibberella zeae, inoculum concentration, Type II resistance.

A giberela do trigo, cujo agente etiológico é o fungo Gibberella zeae (Schwabe.) Petch (Fusarium graminearum Schwabe) é considerada a principal doença de espiga do trigo sul do Brasil. Nos últimos anos, vem ganhando importância, devido aos danos que podem ser quantitativos e qualitativos, e também pelo fato do fungo, sobreviver em restos culturais, ter ampla gama de hospedeiros e seu inóculo estar presente no ar durante todo o ano. Essas características fazem com que algumas estratégias de manejo não sejam muito eficientes, dentre elas o controle químico e a rotação de cultura $(12,23)$.

Por outro lado, a resistência genética, destaca-se com a estratégia mais eficiente e de menor custo (12), apesar disso, verifica-se, que para o patossistema giberela $\mathrm{x}$ trigo, o nível de resistência dos cultivares de trigo disponíveis no mercado não é satisfatório, pois não existem cultivares de trigo com resistência completa ou imunes à doença. De acordo com Mesterhazy (9) existem cinco mecanismos de resistência do trigo à giberela: Tipo I: a resistência à infecção inicial; Tipo II: a resistência à disseminação do fungo na espiga via ráquis; Tipo III: redução do acúmulo de deoxinivalenol (DON); Tipo IV: resistência dos grãos à infecção (mesmo que a espiga esteja infectada) e Tipo V: tolerância (menor perda de produtividade, mesmo com elevada infecção). Segundo Bai e Shaner (4), as resistências dos Tipos I e II são as mais estudadas, e várias metodologias têm sido desenvolvidas 
para avaliar e distinguir esses tipos de resistência pelos melhoristas de plantas. O ideal para os programas de melhoramento genético seria obter cultivares que combinem fatores que condicionam a resistência ou escape à penetração com os que conferem resistência à colonização (11).

Para verificar qual o tipo de resistência do trigo à giberela é necessário utilizar metodologias de inoculação artificial, seja por pulverização de conídios de $F$. graminearum $(2,15,21,24)$ ou pela injeção de conídios na espigueta central $(2,10,15,21)$ durante o período de florescimento.

Com relação à concentração de conídios para a inoculação artificial, sabe-se que dependendo da resistência do cultivar esse valor pode variar. Em trabalhos de inoculação artificial em trigo (15) usou suspensão de conídio na concentração de $4 \times 10^{3}$ conídios $\mathrm{mL}^{-1}$. Pacheco \& Nascimento Junior (10), avaliando espigas de triticale e centeio, inocularam suspensão contendo $5 \times 10^{5}$ conídios $\mathrm{mL}^{-1}$. Alves (2), em testes de reações de cultivares de trigo à giberela, inoculou na espigueta central suspensão de conídios com concentração de $5 \times 10^{4}$ conídios $\mathrm{mL}^{-1}$. Schuster \& Ellner (16), em inoculações dentro das flores do trigo, entre a pálea e a lema e também no exterior das flores, usaram concentrações de $60 \times 10^{3}$ e $50 \times 10^{4}$ conídios $\mathrm{mL}^{-1}$, respectivamente.

Os objetivos desse trabalho foram determinar a concentração ótima de conídios de $F$. graminearum para inoculação artificial em espiguetas de trigo e verificar o tipo de resistência à giberela (Tipo I e/ou II) dos cultivares de trigo.

\section{MATERIAL E MÉTODOS}

Determinação da concentração de conídios de Fusarium graminearum para inoculação artificial de espiguetas de trigo

Os cultivares de trigo avaliados nesses experimento foram Mirante, Pampeano, BRS 208 e BRS 177, sendo classificadas como suscetível (S), moderadamente resistente (MR), moderadamente suscetível (MS) e moderadamente resistente (MR) à giberela (14). As sementes de trigo foram semeadas em vasos plásticos contendo solo hortado e mantidas em câmara de crescimento para inoculação e posterior observação dos sintomas e sinais.

O inóculo de $F$. graminearum foi obtido a partir de sementes de trigo do cultivar BRS Guamirim, oriundas de lavouras no município de Saldanha Marinho - RS, na safra 2011. O micélio de $F$. graminearum foi transferido para placas de Petri, contendo o meio de cultura $1 / 4 \mathrm{BSA}$ (8), sendo as placas incubadas a $25 \pm 2{ }^{\circ} \mathrm{C}$ e com fotoperíodo de 12 horas até obter-se esporulação abundante do fungo. Em seguida, procedeu-se o isolamento monospórico (1).

Na inoculação foi usado o método de injeção com seringa dosadora modificado (15), que consta da injeção da suspensão de conídios na espigueta central da espiga na fase de antese. Nesse trabalho foi substituída a seringa por uma micropipeta, depositando-se uma gota de $0,01 \mathrm{~mL}$ entre a pálea e a lema diretamente sobre o ovário da espigueta central de cada lado da espiga. Após a inoculação, as plantas foram mantidas em câmara climatizada, garantindo o molhamento das espigas por 48 horas a $25 \pm 2{ }^{\circ} \mathrm{C}$. Decorrido esse período, as plantas foram mantidas a $18 \pm 2{ }^{\circ} \mathrm{C}$ até o momento da avaliação.

As concentrações de conídios avaliadas foram $5 \times 10^{3}, 15 \times 10^{3}$, $25 \times 10^{3}, 35 \times 10^{3}$ e $40 \times 10^{3}$ conídios $\mathrm{mL}^{-1}$ e uma testemunha com água. A partir das colônias puras, procedeu-se a quantificação da esporulação, no qual foram adicionados $5 \mathrm{~mL}$ de água destilada na placa de Petri e com o auxílio de um pincel, os conídios foram removidos. A partir da suspensão de conídios, determinou-se o número de conídios em hemacitômetro tipo Neubauer (1) visando quantificar as diferentes concentrações.

As avaliações foram realizadas aos 21 dias após a inoculação, contando-se as espiguetas com sintomas da doença, excluindo as duas que foram inoculadas, visando determinar a incidência de espigas gibereladas (Ieg). Para isso, contou-se o número de espiguetas gibereladas por espiga (Neg) e o total de espiguetas de cada espiga (Te), utilizando a fórmula Ieg $(\%)=\mathrm{Neg} \times \mathrm{Te} / 100$.

O delineamento experimental foi inteiramente casualizado com cinco repetições, no qual cada cultivar foi considerado um experimento. Os dados foram submetidos à análise de regressão polinomial.

Resistência de cultivares de trigo mediante a inoculação artificial de Fusarium graminearum em espiguetas de trigo

Para determinação das resistências do Tipo I e II, as sementes de trigo do cultivar BRS Guamirim foram semeadas em vasos plásticos contendo solo hortado e mantidas em câmera de crescimento. À medida que as plantas atingiram a antese, as espigas selecionadas foram inoculadas. Na inoculação de $F$. graminearum foi usado o método de injeção com seringa dosadora modificado (15) na concentração de 31.000 conídios $\mathrm{mL}^{-1}$. Após a inoculação, as plantas foram mantidas em câmara climatizada garantindo o molhamento das espigas por 48 horas a $25 \pm 2{ }^{\circ} \mathrm{C}$. Decorrido esse período, a temperatura foi reduzida para $18 \pm 2{ }^{\circ} \mathrm{C}$ até o momento da avaliação.

Para a determinação da incidência de espiguetas gibereladas (Ieg), as avaliações foram realizadas aos 7, 14 e 21 dias após a inoculação na mesma espiga, contando-se as espiguetas com sintomas da doença, excluindo as duas que foram inoculadas. A avaliação da severidade da doença foi realizada 21 dias após a inoculação, no estádio de espiga verde pela escala diagramática de Stack \& McMullen (20) e no estádio de espiga seca, a porcentagem de grãos giberelados.

$\mathrm{O}$ delineamento experimental foi inteiramente casualizado com seis repetições. Os dados foram analisados usando o software Assistat (17), e as médias submetidas ao teste de Tukey a 5\% de probabilidade.

\section{RESULTADOS E DISCUSSÃO}

Determinação da concentração de conídios de Fusarium graminearum para inoculação artificial de espiguetas de trigo

Observou-se que independente da concentração de inóculo de $F$. graminerum, houve $100 \%$ de infecção das espiguetas inoculadas para todos os cultivares. Isso comprova a eficiência do método de inoculação empregado. Resultado semelhante ao desse trabalho foi observado por Schuster e Ellner (16), que ao inocularem a suspensão de conídios de $F$. graminearum no ovário das espiguetas, verificaram que os sintomas de infecção foram mais evidentes do que quando inoculados fora da espigueta. Além disso, verificou-se que a concentração ótima do inóculo do fungo variou em função do cultivar, sendo que a média dos cultivares foi de $26 \times 10^{3}$ conídios $\mathrm{mL}^{-1}$. Nesse trabalho optou-se por trabalhar com a maior concentração de conídios, que foi obtida no cultivar Mirante.

Observou-se que, à medida que houve aumento da concentração do inóculo de fungo, ocorreu incremento na Ieg (incidência de espiga giberelada), independente do cultivar, atingindo o nível mais alto (ponto máximo) no gráfico da variável avaliada, para posteriormente, diminuição com o aumento da concentração do inóculo. A maior Ieg ocorreu no cultivar Mirante (Figura 1), cuja equação: $y=-5 E-08 x^{2}$ $+0,0031 x$, determinou que a melhor concentração do inóculo foi de $31 \times 10^{3}$ conídios $\mathrm{mL}^{-1}$. Da mesma maneira procedeu-se para as demais cultivares, sendo que para o cultivar BRS 177 (Figura 2), obteve-se a equação: $\mathrm{y}=-3 \mathrm{E}-08 \mathrm{x}^{2}+0,0014 \mathrm{x},\left(23.5 \times 10^{3}\right.$ conídios $\left.\mathrm{mL}^{-1}\right)$, para 
o cultivar BRS 208 (Figura 3), obteve-se a equação: $y=-7 E-08 x^{2}$ $+0,0034 \mathrm{x},\left(24.5 \times 10^{3}\right.$ conídios $\left.\mathrm{mL}^{-1}\right)$ e para o cultivar Pampeano (Figura 4), obteve-se a equação: $y=-3 \mathrm{E}-08 \mathrm{x}^{2}+0,0015 \mathrm{x},\left(25 \times 10^{3}\right.$ conídios $\left.\mathrm{mL}^{-1}\right)$, sendo esta última a menor Ieg. Apesar de cada cultivar apresentar uma concentração ótima para inoculação artificial, devido aos diferentes níveis de resistência das mesmas, optou-se por utilizar a melhor concentração que foi de $31 \times 10^{3}$ conídios $\mathrm{mL}^{-1}$ que foi obtido no cultivar de trigo Mirante.

Dados semelhantes ao desse trabalho foram obtidos por Stack (19) e Telles Neto (21), os quais testaram diferentes concentrações de ascósporos de $G$. zeae e de macroconídios de $F$. graminearum, que resultaram no aumento crescente da intensidade da giberela com o aumento da concentração de inóculo, e que após atingir o nível mais alto de severidade da doença, houve redução da doença. Assim como, para Barba (6), no patossistema Bipolaris sorokiniana (Sacc.) x trigo e Camera (7) no patossistema Cercospora sojina Hara x soja. Esse aumento, e posterior decréscimo na severidade das doenças com o aumento do inóculo podem ser atribuídos ao fato que, altas densidades de inóculo podem produzir efeito antagônico na germinação dos esporos, ou vários esporos podem participar de uma única infecção ou ainda autoinibição da germinação dos esporos por um número limitado de sítios de infecção (6).

Resistência de cultivares de trigo mediante a inoculação artificial de Fusarium graminearum em espiguetas de trigo

Para a avaliação da resistência do Tipo I, verificou-se que a

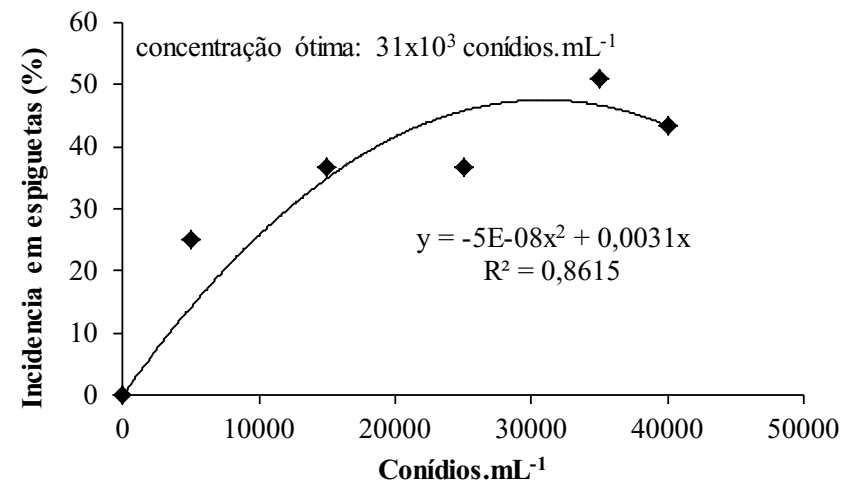

Figura 1. Efeito da concentração de inóculo de Fusarium graminearum sobre a incidência de espiguetas gibereladas na cultivar Mirante. UPF, Passo Fundo. RS. 2012.

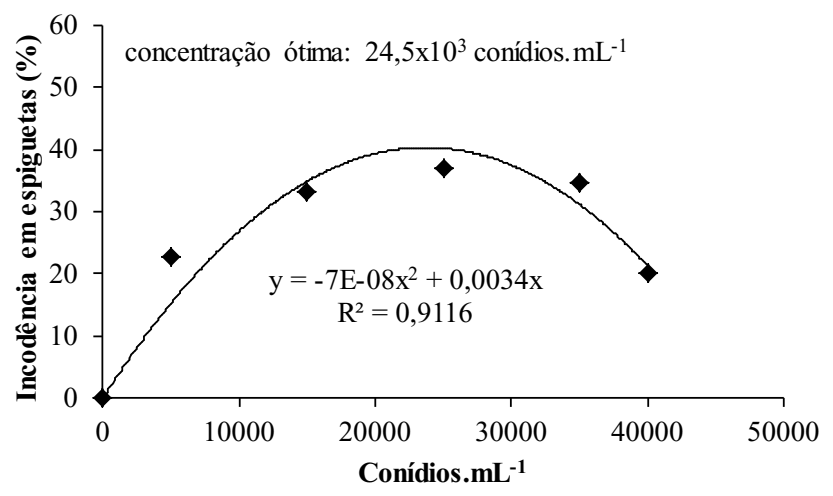

Figura 3. Efeito da concentração de inóculo de Fusarium graminearum sobre a incidência de espiguetas gibereladas na cultivar BRS 208. UPF, Passo Fundo, RS. 2012. severidade foi maior para os cultivares de trigo BRS 177 e Pampeano, sendo que as mesmas diferiram estatisticamente dos demais cultivares. Para percentagem de grão giberelado, observou que o cultivar BRS 177 foi estatisticamente superior aos demais cultivares (Tabela 1). Para a avaliação da resistência do Tipo II, independente do cultivar de trigo houve progressão da doença com o passar do tempo, sendo que aos 7 DAI, não houve diferença estatística entre os cultivares. Aos $14 \mathrm{e}$ 21 DAI, os cultivares BRS 177 e Pampeano apresentaram os maiores valores de Ieg diferindo estatisticamente dos demais cultivares, seguido pelos cultivares Mirante e BRS 208, que foram estatisticamente iguais (Tabela 1). Portanto, os cultivares Mirante e BRS 208, não possuem resistência à giberela do Tipo II (14), pois quando as espiguetas foram inoculadas, a infecção atingiu rapidamente o ráquis, comprometendo toda a espiga, não ficando restrita somente ao ponto de inoculação, mas disseminou-se para as demais espiguetas. Para os cultivares Pampeano e BRS 177 não houve diferença estatística independente do número de dias após a inoculação, verificando que a resistência à giberela é do Tipo II, pois não houve disseminação da infecção para outras espiguetas. Essa última cultivar, apesar de não ser mais recomenda para plantio no sul do Brasil $(13,14)$, continua sendo importante como fonte de resistência à giberela em programas de melhoramento genético.

Segundo Alves (2), as cultivares Pampeano, Ônix, Rubi, Abalone, BRS 179, BRS Louro, BRS Guamirim, CEP 50, CD 114, CD 120 e CDF 2002116, apresentaram resistência do Tipo II. A resistência demonstrada pela cultivar Pampeano, pode ser atribuída pela herança genética da cultivar, que tem em sua genealogia a cultivar chinês Sumai 3 , muito

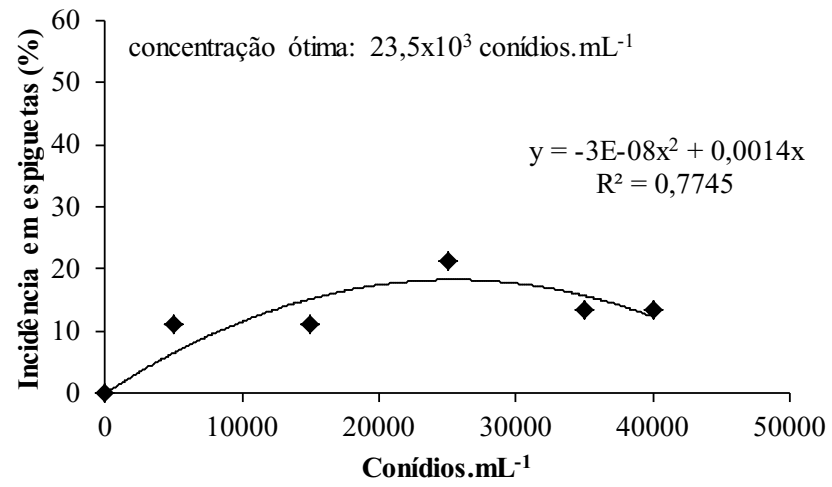

Figura 2. Efeito da concentração de inóculo de Fusarium graminearum sobre a incidência de espiguetas gibereladas na cultivar BRS 177. UPF, Passo Fundo, RS. 2012.

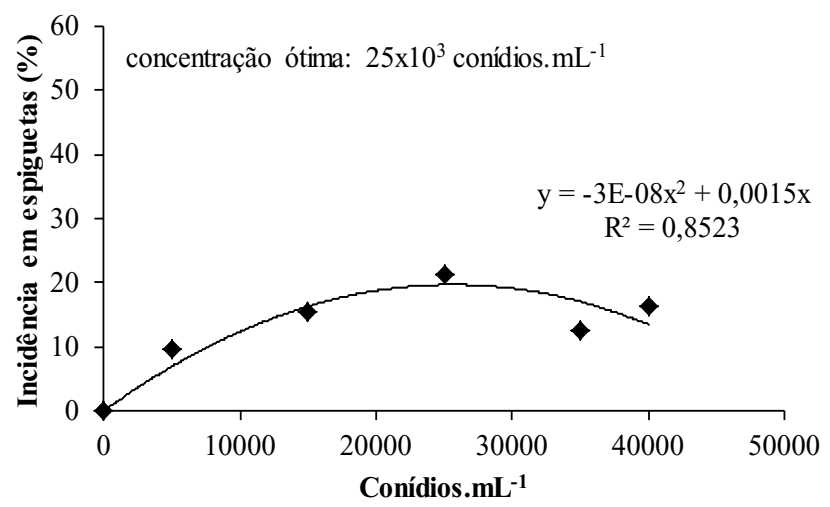

Figura 4. Efeito da concentração de inóculo de Fusarium graminearum sobre a incidência de espiguetas gibereladas na cultivar Pampeano. UPF, Passo Fundo, RS. 2012. 
Tabela 1. Severidade de giberela (\%), grão giberelado (\%) e incidência em espiguetas gibereladas (\%) aos 7, 14 e 21 dias após a inoculação (DAI) em quatro cultivares de trigo. UPF, Passo Fundo, RS, 2012

\begin{tabular}{|c|c|c|c|c|c|}
\hline \multirow{2}{*}{ Cultivares } & \multirow{2}{*}{ Severidade } & \multirow{2}{*}{ Grão giberelado } & \multicolumn{3}{|c|}{ Incidência em espiguetas gibereladas } \\
\hline & & & 7 DAI & 14 DAI & $21 \mathrm{DAI}$ \\
\hline Mirante & $5,9 b^{2}$ & $2,2 \mathrm{~b}$ & $13,8 \mathrm{a}$ & $33,3 \mathrm{~b}$ & $61,7 \mathrm{~b}$ \\
\hline BRS 208 & $6,7 \mathrm{~b}$ & $2,5 \mathrm{~b}$ & $15,6 \mathrm{a}$ & $35,6 \mathrm{~b}$ & $57,0 \mathrm{~b}$ \\
\hline BRS 177 & $8,9 \mathrm{a}$ & $9,1 \mathrm{a}$ & $12,9 \mathrm{a}$ & $18,2 \mathrm{a}$ & $30,1 \mathrm{a}$ \\
\hline Pampeano & $9,2 \mathrm{a}$ & $2,8 \mathrm{~b}$ & $12,8 \mathrm{a}$ & $16,2 \mathrm{a}$ & $21,3 \mathrm{a}$ \\
\hline C.V(\%) & 14,58 & 12,23 & 16,11 & 12,34 & 11,31 \\
\hline
\end{tabular}

${ }^{1}$ Médias seguidas por mesmas letras não diferem entre si pelo teste de Tukey a $5 \%$ de probabilidade do erro.

estudado e conhecido como fonte de resistência à giberela $(3,22)$. Van Ginkel et al. (22) utilizando cultivares de trigo derivadas de Sumai 3, observaram dois genes dominantes para resistência do Tipo II. Alves (2), avaliando a reação de cultivares de trigo à resistência do Tipo II em casa-de-vegetação, verificou que a cultivar Frontana, utilizada em programas de melhoramento como fonte de resistência à giberela $(5$, 9), não demonstrou resistência para expansão da doença na espiga. Por outro lado, Singh et al (18) relataram baixa incidência da doença nessa cultivar no campo. Esses resultados demonstram que, cultivares com bons níveis de resistência à giberela no campo, podem não apresentar o mesmo resultados quando o fungo é inoculado artificialmente em ambientes controlados. Sendo assim, cultivares que apresentam resistência do Tipo I, ou seja, resistência à infecção inicial, podem não apresentar mecanismos que impeçam a progressão da doença, ou seja, resistência do Tipo II.

A concentração ótima para inoculação artificial de giberela em espiguetas de trigo é de $31 \times 10^{3}$ conídios $\mathrm{mL}^{-1}$.

As cultivares Pampeano e BRS 177 não apresentam resistência do Tipo I à giberela, porém apresentam do Tipo II, enquanto que as cultivares Mirante e BRS 208 não apresentam nenhum dos dois tipos de resistência.

\section{REFERÊNCIAS BIBLIOGRÁFICAS}

1. Alfenas, A. C.; Mafia, R. G. Métodos em Fitopatologia. Viçosa: Editora UFV, 2007. $382 \mathrm{p}$.

2. Alves, R. H. Reação de resistência à giberela em cultivares de trigo (Triticum aestivum L.), avaliada em condições de campo e casa de vegetação. 2010. 57f. Dissertação (Mestrado em Agronomia) - Universidade Estadual do Oeste do Paraná, Campus de Marechal Cândido Rondon.

3. Bai, G.H; Shaner, G.; Ohm, H. Inheritance of resistance to Fusarium graminearum in wheat. Theorical and Applied Genetics, Heidelberg, v.100. p.1-8, 2000.

4. Bai, G.; Shaner, G. Scab of wheat: Prospects for control. Plant Disease, Saint Paul v.78, p.760-765, 1994.

5. Ban, T. Studies on the genetics of resistance to Fusarium head blight caused by Fusarium graminearum Schwabe in wheat (Triticum aestivum L.). Bulletin of the Kyushu National Agricultural Experiment Station, Oram, V.38, p.27-78, 2001.

6. Barba, J.T. Bipolaris sorokiniana (Cochliobolus sativus) em sementes de cevada: detecção, transmissão e controle. 2000. 196f. Dissertação (Mestrado em Agronomia) - Faculdade de Agronomia e Medicina Veterinária, Universidade de Passo Fundo, Passo Fundo.

7. Camera, J. N Patogenicidade e esporulação de Cercospora sojina e interação entre temperatura e período de molhamento foliar na intensidade da mancha foliar "olho-de-rã" em soja. 2012. 113 f. Dissertação (Mestrado em Agronomia) - Faculdade de Agronomia e Medicina Veterinária, Universidade de Passo Fundo, Passo Fundo.

8. Fernandez, M. R. Manual para laboratório de fitopatologia. Passo Fundo, EMBRAPA-CNPT, 1993. 128p. (EMBRAPA-CNPT. Docu, mentos, 6).

9. Mesterhazy, A. Types and components of resistance to Fusarium head blight of wheat. Plant Breeding, Berlin, v.114, p.377-386, 1995.

10. Pacheco, H.; Nascimento Junior, A. Do. Método para infecção e avaliação de giberela em espigas de triticale e de centeio na Embrapa Trigo. In: Lau, D., Pimentel, M. B. M., Santos, M. O. (Org.) Mostra de iniciação científica da Embrapa Trigo, 6., 2010, Passo Fundo. Resumos... Passo Fundo: Embrapa Trigo, 2010. 36 p. html. (Embrapa Trigo. Documentos Online, 123). Disponível em: <http://www.cnpt.embrapa. br/biblio/do/p_do123.htm>. Acesso em: 08 de jun. 2011.

11. Reis, E. M. Doenças do trigo III - Giberela. 2ed. revisada e ampliada. Passo Fundo: Editora UPF, 1988. 13p.

12. Reis, E.M.; Baruffi, D.; Remor, L. and Zanatta, M.. Decomposition of corn and soybean residues under field conditions and their role as inoculum source. Summa phytopathologica., vol.37, n.1, p.65-67. 2011

13. Reunião da comissão brasileira de pesquisa de trigo e triticale. Informações técnicas para trigo e triticale - safra 2011 / IV Reunião da Comissão Brasileira de Pesquisa de Trigo e Triticale, Cascavel: COODETEC, 2010. 170p.

14. Reunião da comissão brasileira de pesquisa de trigo e triticale. (8: 2014: Canela, RS) Informações técnicas para trigo e triticale - SAFRA 2014 / XV Reunião da Comissão Brasileira de Pesquisa de Trigo e Triticale, Canela RS, 25 a 28 de julho de 2014. Canela, RS: Embrapa Trigo, 2014. 229p.

15. Sartori, J. F. Evaluacíon de restencia a fusariosis del trigo en condiciones controladas y en campo. In: Taller sobre la fusarioses de la espiga em America del Sur. M. M Kohli (Org.) Mexico D. F. CIMMYT. 1989. p.71-75.

16. Schuster, R.; Ellner, F. M. Level of Fusarium infection in wheat spikelets related to location and number of inoculated spores. Mycotoxin Research, Washington, v.24, No. 2 . p.80-87, 2008.

17. Silva, F. DE A. S. E.; Azevedo, C. A. V. DE. Versão do programa computacional Assistat para o sistema operacional Windows. Revista Brasileira de Produtos Agroindustriais, Campina Grande, v.4 ,n.1, p.71-78, 2002.

18. Singh, R. P., MA, H., And Rajaram, S. Genetic analysis of resistance to scab in spring wheat cultivar Frontana. Plant Disease, Saint Paul, v.79, p.238-240, 1995 .

19. Stack, R. W. A comparison of the inoculum potential of ascospores and conidia of Gibberella zeae. Canadian Journal of Plant Patholology, Ottawa, v.11, p.137-142, 1989.

20. Stack, R.W.; Mcmullen, M.P. A visual scale to estimate severity of fusarium head blight in wheat. Fargo: North Dakota State University - Extension Service, 1995. p.1095

21. Telles Neto, F. X. B. Transmissão e controle de Fusarium graminearum em sementes e danos causados por giberela em trigo. 2004, $113 \mathrm{f}$. Dissertação (Mestrado em Agronomia). Faculdade de Agronomia e Medicina veterinária, Universidade de Passo Fundo, Passo Fundo.

22. Van Ginkel, M.; Van Der Schaar, W.; Zhuping, Y.; Rajaram, S. Inheritance 
of resistance to scab in two wheat cultivars from Brazil and China. Plant Disease, Saint Paul, v.80, p.863-867, 1996.

23. Viana, E.; Deuner, C. C. Sobrevivência. In: REIS, E. M. Seminário sobre Giberela em Cereais de Inverno. Coletânea de Trabalhos. Passo Fundo: Berthier, 2011.p.43-54.
24. Zoldan, S. M. Regiões de risco, Caracterização da antese em cereais de inverno e Sistema de alerta para giberela, em trigo. 2008. 196f. Dissertação (Mestrado em Agronomia) - Faculdade de Agronomia e Medicina veterinária, Universidade de Passo Fundo. Passo Fundo, RS. 